\title{
FIFTY YEARS OF ORTHOPAEDIC SURGERY IN GANADA
}

\author{
R. I. Harris, TORONTO \\ W. E. Gallie, Toronto \\ A. McLachlin, London, Ontario \\ J. A. Nitter, Montreal
}

\author{
T. B. ACKer, Halifax, N.S. \\ A. GiBSon, WinNipeg \\ F. H. H. Mewburn, Edmonton \\ J. P. Patterson, Vancouver
}

Canada is a country so vast that the development of orthopaedic surgery has not followed the same uniform plan as in smaller and more compact countries. The university centres of Toronto and Montreal have gained inspiration from England and stimulus from the United States; London and Kingston, Ontario, are competing with Toronto; Montreal, the second largest "French" city in the world, shares with Quebec its inspiration from France; Winnipeg still represents the Middle-West with its staunch adherence to " the old country "; Edmonton in Alberta has one of the richest as well as the youngest of medical schools; Vancouver in British Columbia has recently appointed its first professor of surgery; and Newfoundland and the Maritime Provinces have been influenced no less by New England than by England. In this great country, with its multiplicity of influences, the development of orthopaedic surgery can be considered best on a regional basis.

\section{ORTHOPAEDIC SURGERY IN TORONTO}

In Toronto, as in many other centres, orthopaedic surgery had its beginnings in a special interest taken by certain general surgeons in the deformities and deforming diseases of childhood. Before 1900 all cases now grouped as orthopaedic were treated by the general surgical staff, much as were the cases now segregated as thoracic, neurosurgical, vascular, urological, plastic and so on. From that time on, however, certain general surgeons began to take interest in special fields and laid the foundations for the development of various surgical specialities. Orthopaedic surgery was one of these and its founder in Toronto was Clarence Leslie Starr.

Under Starr's leadership there developed at the Hospital for Sick Children a school of orthopaedic surgery which quickly took a leading place in Canada and indeed in the whole of America; the group worked together in the greatest harmony for many years, both in peace-time and in war, always stimulating and helping one another, and always striving to advance scientific knowledge and enhance the reputation of their school. Death and retirement alone interfered with this delightful association, and even then the gaps were ably filled.

In early days, before the first world war, the field was not wide and did not merit segregation. However, with the tremendous advance that occurred during the war, adding as it did all sorts of lesions of bones, joints, nerves and the deformities resulting therefrom, and many of the problems now dealt with by plastic surgeons, the necessity for specialisation became very evident and soon was in full process of development. The speciality is still broadening and is now encroaching on the field of trauma.

Looking back over the years it is interesting to recall some of the special studies that engaged the attention of these men. In the early days at the Children's Hospital a large proportion of the patients suffered from tuberculosis of bones and joints. Starr's chief interest for many years was the prevention of secondary infection in tuberculous abscesses. In this he tried Lister's method of incision and drainage with infrequent antiseptic dressings; then aspiration and injection with iodoform emulsion; and finally, after a visit to Barker at University College Hospital, London, incision, evacuation, curettage and closure. While 
these efforts were not always successful there was, nevertheless, a striking reduction in the secondary infections. No further progress was made in this direction until antibiotics were discovered. An interesting study was then instituted by Coulthard at the Toronto Hospital for Consumptives, under the guidance of R. I. Harris; and great progress was made.

A problem that always interested Starr was osteomyelitis and he published several papers which guided most Canadian and American surgeons for many years. His chief dictum was " early and adequate drainage without increasing the necrosis." With the discovery of the sulfonamides and later, penicillin, a concerted attack was again made on this disease under the leadership of D. E. Robertson and F. R. Wilkinson, and their papers were among the earliest to record the marvellous influence of these drugs.

Early in the century several epidemics of poliomyelitis in Ontario left a broad trail marked by great numbers of crippled children. These cases enabled the young orthopaedic surgeons to try out the possibility of converting the tendons of paralysed muscles into

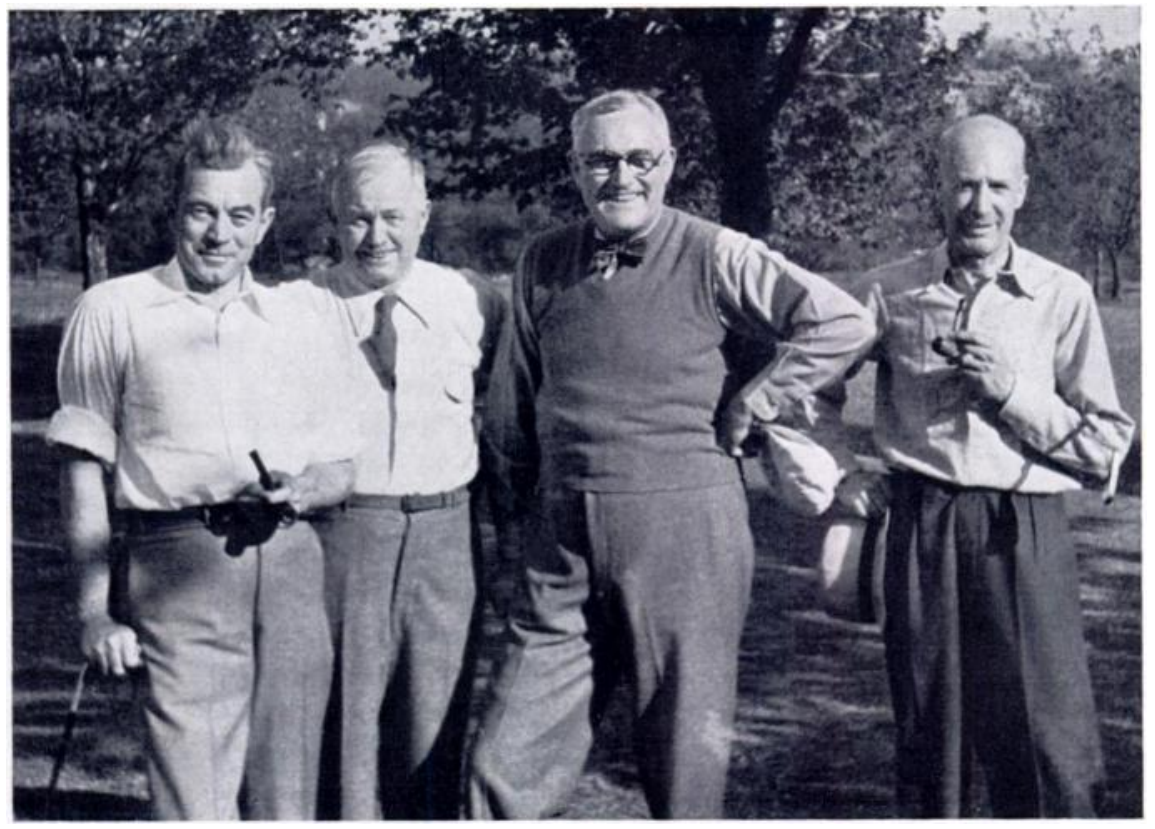

R. I. Harris, I. E. Robertson, W. E. Gallie, A. B. Le Mesurier.

ligaments and develop an operation called " tendon fixation." Several papers came from the pen of W. E. Gallie and for a time it was hoped that an important contribution had been made. The passage of years unfortunately showed that the results of the operation were uncertain and often impermanent, and it has been largely replaced by other methods.

About 1911 great interest arose in the transplantation of bone. Many of the principles had been laid down by Macewen, Ollier and Axhausen, but it remained for Albee to demonstrate the great practical value of the idea and to develop a simple technique. Recognising that this was perhaps the most important contribution that was likely to be made to the surgery of bone for a long time, Gallie and Robertson undertook a series of experiments on animals in order to test previous statements and, if possible, to add something to the sum of knowledge on the subject. This study, leading to a series of papers, the last of which was published in the British Journal of Surgery in 1919, formed the basis of teaching of the surgery of bone in the Toronto school.

The war of 1914-18 was perhaps the strongest influence in establishing orthopaedic 
surgery as a speciality in Canada. Not only did it provide the opportunity to test newly acquired knowledge of the surgery of bone, but it opened whole new fields in the surgery of tendons, ligaments, nerves and muscles. It certainly broadened the field sufficiently to attract men who otherwise would have continued in general surgery. Among the problems presented was that of amputations. Early in 1915, largely on the advice of Professor Starr, the Government adopted a policy of establishing its own artificial-limb factory and supervising the subsequent medical care of amputees. This gave A. B. Le Mesurier and (iordon Iale, who were made surgical consultants on amputations and artificial limbs, the opportunity to observe thousands of amputation cases and, figuratively, to watch them march down the years.

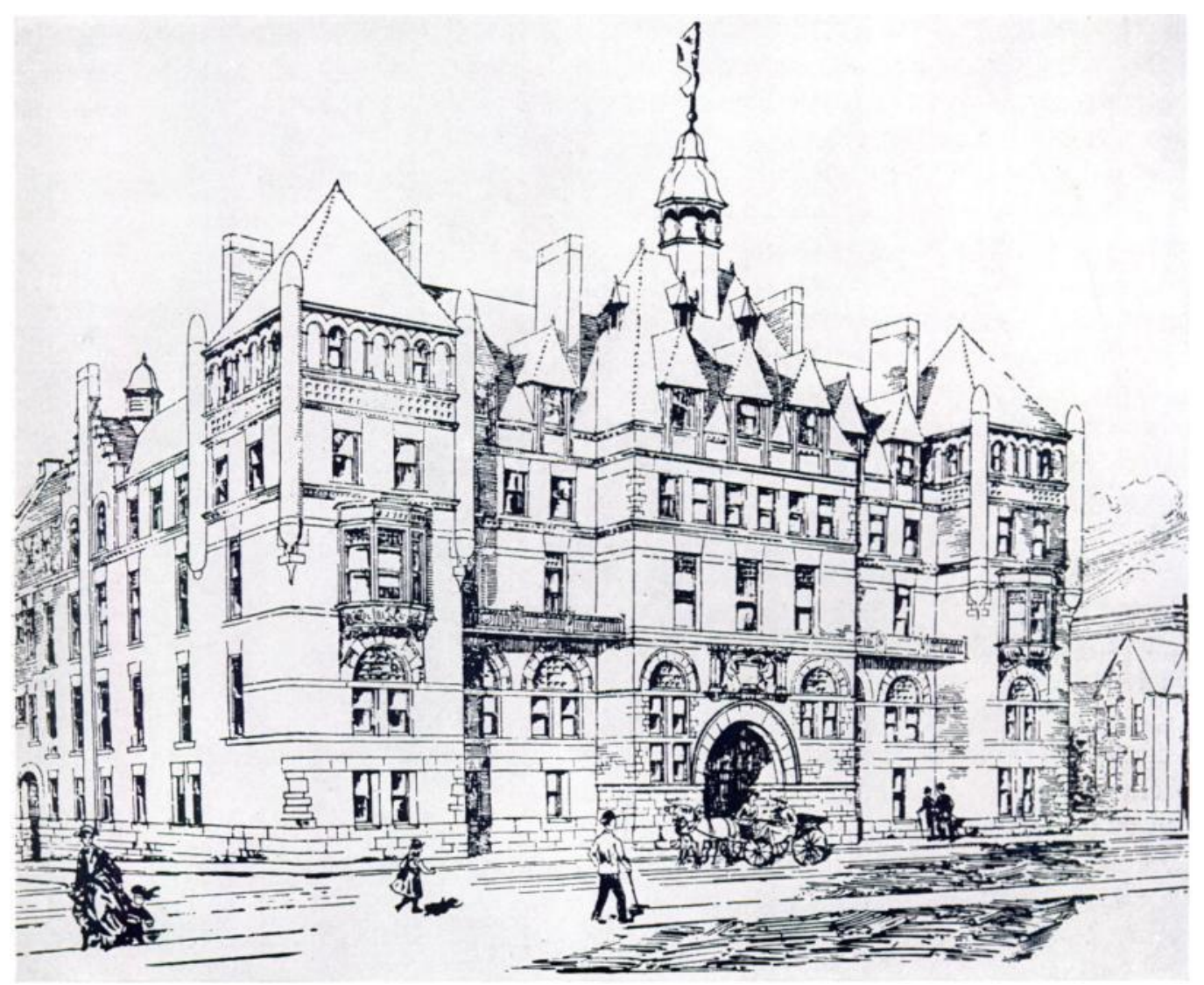

Hospital for Sick Children, Toronto. Architect's original drawing of the old building now being replaced. The corner-stone of this building was laid in September 1889.

This opportunity led them to the very definite opinion (which has been called the " Canadian opinion ") that end-bearing stumps from Syme and Gritti-Stokes operations had great merit. Their influence accounts largely for the popularity of these operations in America.

The concentration of all cases of surgical tuberculosis in the Veterans' Hospital in Toronto gave R. I. Harris the opportunity to make an extensive study of the relationship of tuberculosis in bone to tuberculosis in the urinary and genital tracts. His paper “Tuberculous Bacilluria," published in the British Journal of Surgery in January 1929, attracted marked attention.

The most important contribution made by Bruce Robertson during his short life was not connected exclusively with orthopaedic surgery but was equally important in all forms of surgery complicated by haemorrhage and shock. Early in his career he became interested

YOL. $32 \mathrm{~B}$, No. 4, NOYEMBER 1950 
in the newly discovered technique of blood transfusion. When the Canadian army went to France he performed the first blood transfusion ever done in battle. His work with No. 2 Canadian Casualty Clearing Station at Remy Siding was observed by the British consultants, Gordon-Taylor, W. Anderson and John Fraser, and led to the widespread use of this method in the British Army. Robertson later developed the method known as "exsanguination transfusion " in an attempt to get rid of the toxaemia of burns; it was of course not the answer to the problem but the method still exists in the treatment of new-born infants with a defective rhesus factor.

Attracted by the demonstration of Kirschner that fascia lata could be transplanted to another place in the same animal and survive, Gallie and Le Mesurier carried out a long series of experiments on animals which led to the "living suture" operation for hernia and the repair of various injuries of ligaments. A series of papers was published, the last of which formed the basis of a Hunterian Lecture delivered at the Royal College of Surgeons in 1924. Since then the principle has been applied in the treatment of recurring dislocation of the shoulder, and a series of two hundred operations was reported in a Moynihan lecture in 1947.

The visit of Royle and Hunter to Canada in $\mathbf{1 9 2 5}$ aroused great interest among the staff of the Children's Hospital in the possibilities of sympathetic ramisection and ganglionectomy in infantile paralysis. The two Robertsons, R. I. Harris and J. L. McDonald explored the field thoroughly; Harris ultimately demonstrated that ganglionectomy on the paralysed side not only retarded shortening but in some cases actually lessened the shortening already present. This observation has not received the attention it deserves, but has recently been commented on favourably by Barr of Boston.

In the absence of clear limitations of the field of orthopaedic surgery, overlapping has naturally occurred. Thus, Le Mesurier has taken great interest in the treatment of harelip and cleft palate, and his papers have standardised the treatment of this deformity. Again, the researches of A. W. Farmer, involving the interest of both the orthopaedic and the plastic surgeon, have been directed to the repair of tendons and their sheaths. His suggestion, too, that skin avulsed in accidents could be cleansed, freed of subcutaneous tissue and used as a whole-thickness graft has had wide acceptance.

Stimulated by the physiological studies of Professor Charles Best on " heparin," Gordon Murray undertook an exhaustive series of experiments on animals, and later on patients, which established the importance of anticoagulants in the prevention of venous thrombosis and pulmonary embolism. These studies were reported in a Hunterian Lecture in 1939 and have not only been of value to the orthopaedic and general surgeon but have led to great widening of the field of vascular surgery.

R. I. Harris's Hunterian Lecture in 1949 on spondylolisthesis was a masterly review. Based on a huge clinical experience and careful study of all his cases he has evolved a technique in treatment which appears to be infallible. That the honorary fellowship of the Royal College of Surgeons of England was conferred upon him at the time of this lecture was widely appreciated by Canadians.

The close relationship between orthopaedic and traumatic surgery has always interested the Toronto group of surgeons. Papers by Gordon Murray on bone grafting in non-union in fractures of the carpal scaphoid, on intramedullary wiring in fractures of the clavicle and other bones, and on external pin fixation in badly comminuted Colles fractures have aroused favourable comment. Other papers by Harris on reduction of fractures of the os calcis, by Gallie and Lewis on non-union in fractures of the neck of the femur in the aged, by Gallie, White and Charles Harris on arthrodesis in the subastragalar and ankle joints, and by McDonald on fractures of the elbow have had their place. The contribution of J. L. McDonald towards bettering the treatment of fractures under the Workmen's Compensation Board was outstanding.

The gradual delineation of orthopaedic surgery as a speciality has had its effect on the 


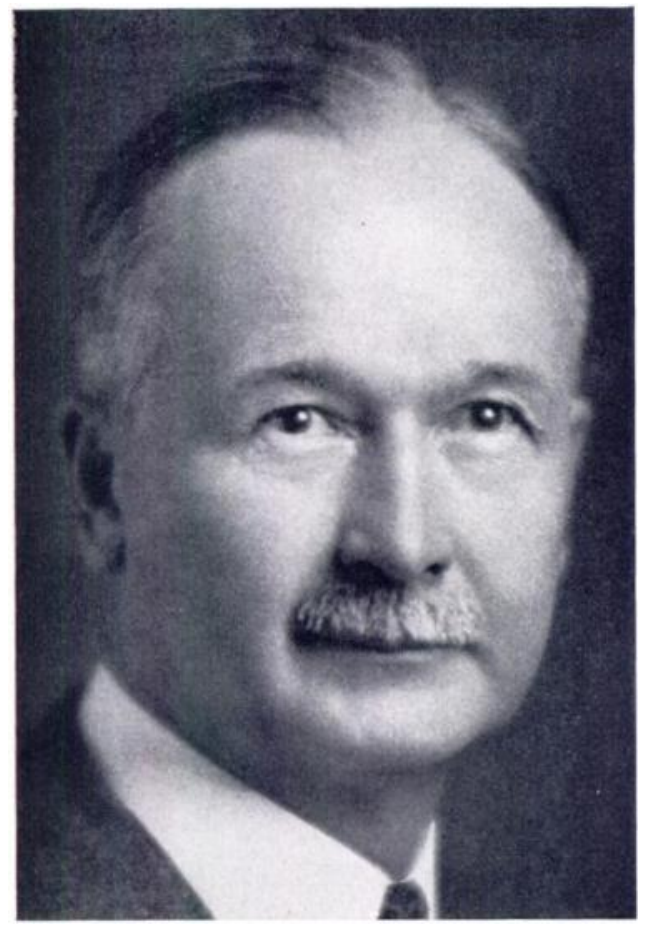

(iarexce Leshile Śtark (1867-1920).

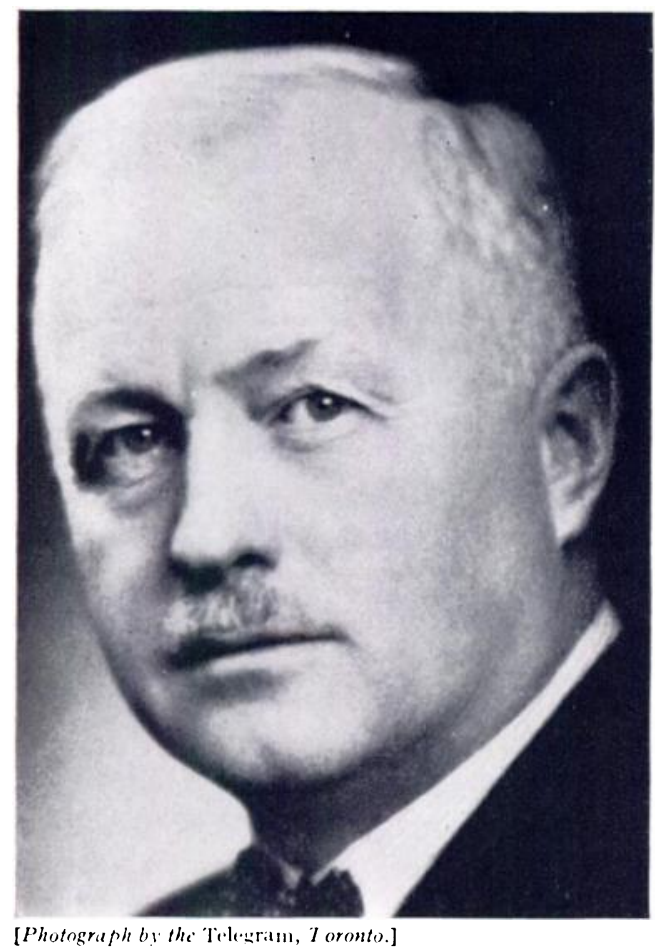

DAVIN ENWARI RORERTSON (18S4-1944).

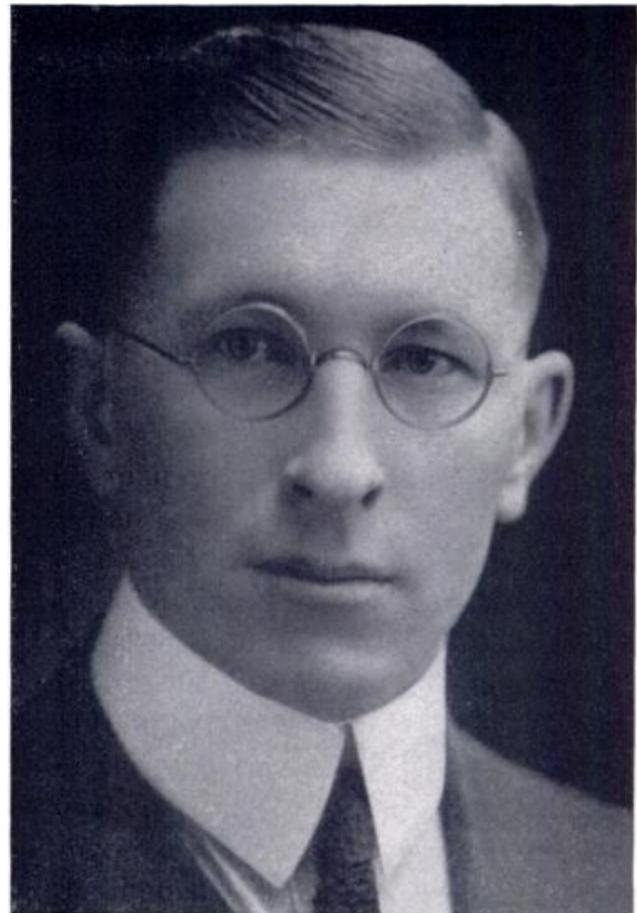

Frenterick (;. BANTING (1891 1941).

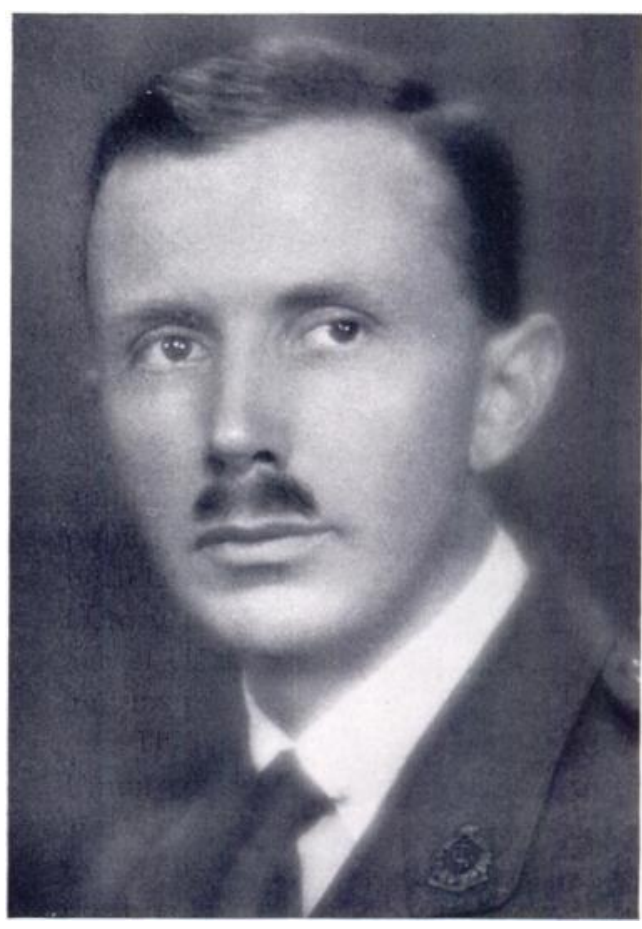

l. BRt'CE ROBERTSON (1885-1923).

VOL. $32 \mathrm{~B}$, NO. 4, NOYEMBER 1950 
staff organisation of the Toronto hospitals. Whereas twenty-five years ago no special orthopaedic services were recognised, now almost all hospitals have such services. At the General Hospital a large and very active division has been organised under the direction of R. I. Harris, assisted by F. P. Dewar and D. McIntosh. At St. Michael's, the Western, the East General and St. Joseph's hospitals a beginning has been made in establishing similar services under the direction respectively of Paul McGoey, A. W. M. White, Leslie Black and H. M. Coleman, and George Pennel. In the university hospitals these orthopaedic services share in undergraduate teaching and in the graduate-training of general surgeons. By an arrangement between the General and the Children's Hospitals a residency system has been established which offers adequate training for specialists.

During and after both wars the Toronto group made important contributions to the welfare of our troops. In the war of 1914-18 Colonel C. L. Starr organised and led into successful operation the Canadian Orthopaedic Service overseas and subsequently-as Consultant to the Director-General of Medical Services and the Department of Veterans' Affairs-an efficient nation-wide service. Outstanding were the organisation and operation of

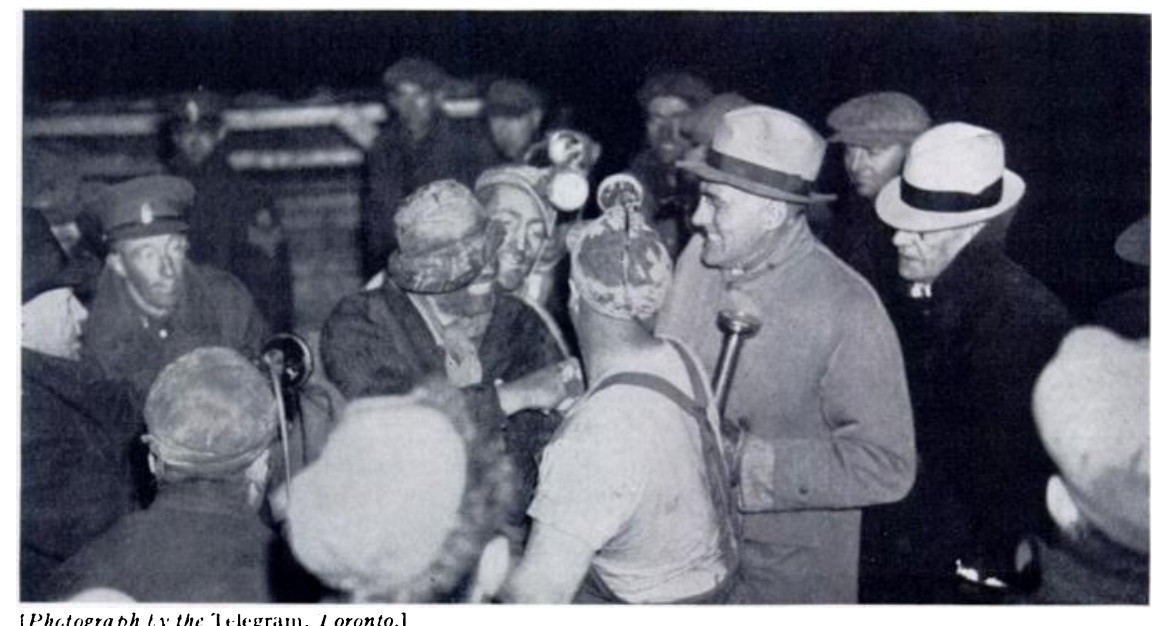

Rescue of D. E. Robertson from Moose River mine, April 23, 1936.

government amputation clinics and an artificial-limb factory, which have stood the test of thirty years. In the recent war the leadership devolved upon Colonel R. I. Harris whose position as Consultant to the Director-General of Medical Services enabled him to ensure efficient organisation and to conduct important research. Outstanding in this was a study of foot defects in soldiers, which was based on a detailed study of the feet of four thousand men. It led to a monumental report by Harris and Beath which will undoubtedly standardise opinion and practice in regard to the feet of soldiers.

A peace-time activity which has interested this group has been the establishment and management of clinics for crippled children all over the Province of Ontario. At suitable intervals a team of orthopaedic surgeons goes out to the various towns and cities, sometimes as far as five hundred miles, and with the aid of the Ontario Society for Crippled Children and one of the Service Clubs, rounds up between one and two hundred out-patients and gives advice on treatment. Those requiring special hospital care are sent to one of the established children's or orthopaedic hospitals. In this way the benefits of scientific medicine are brought to districts where no specialist services exist.

The passage of the years has brought international recognition and many honours to the group. Five have been presidents of the American Orthopaedic Association, three have been 
Hunterian Professors in the Royal College of Surgeons of England, one was made an honorary Fellow and one was a recipient of the honorary medal of the College.

Aside from the excitements and triumphs of two great wars the most thrilling moment in the lives of two senior members of the group came at midnight on April 23, 1936, when D. E. Robertson was brought out alive from the Moose River Gold Mine disaster. Eleven days' incarceration in that black hole, with hardly a hope of rescue, completely failed to daunt his spirit; and he was to live for many years as the distinguished head of the Department of Surgery at the Children's Hospital. A photograph on the preceding page shows the hero of the occasion being welcomed back to this life by Gallie and a great throng of onlookers, well-wishers and friends.

Delightful associations have been made with both the British and the Americans which were immensely strengthened in 1948 during the combined meeting in Quebec under the presidencies of Malkin and Harris. Such intimate contacts remind us that the isolation of former years is over and that we must be prepared to take an increasingly important part in the deliberations of orthopaedic surgeons wherever our language is spoken. The preparation of this account of the orthopaedic surgery of Toronto has given vivid and happy recollections to the writer, who is now retired, and has made him reflect on his good fortune in being associated with so charming and gifted a group of men.

\section{WESTERN ONTARIO}

The history of orthopaedic surgery in Western Ontario is confined almost entirely to this century. Dr B. E. MacKenzie of the Orthopaedic Hospital in Toronto began to pay regular visits to the area about the year 1900; and Dr Stewart Wright, one of MacKenzie's pupils and a member of the staff of the Western Hospital in Toronto, continued this work. Another general surgeon with a special interest in orthopaedics was Dr Hadley Williams. Born in England in 1864, he graduated from the University of Western Ontario in 1888. After training in England and acquiring the English Fellowship he returned to the University of Western Ontario as Professor of Surgery in 1909 and continued in this position until his death in 1932.

It is of interest that Frederick Banting, who later became famous for his work on insulin, was the first surgeon to limit his practice to orthopaedics in Western Ontario. After working in the hospital for Sick Children in Toronto he came to London, Ontario, in 1920 to practise orthopaedic surgery and teach in the department of physiology of the medical school of the University of Western Ontario. He remained only a year before he returned to Toronto with the idea that led to his great discovery. His reception in London had been disappointing, but it is recorded that he was the first to administer blood transfusions to children in Western Ontario, following the teaching of Bruce Robertson of the Hospital for Sick Children in Toronto.

The War Memorial Children's Hospital in London was opened in 1922. The late Dr George Ramsay was prominent in its development from the outset. After obtaining surgical training in the Presbyterian Hospital in Chicago in 1913, he had served overseas in the first world war and spent some time with Sir Robert Jones in Liverpool after the war. He was keenly interested in the Children's Hospital and began gradually to confine his practice to orthopaedic work. When the Ontario Society for Crippled Children was founded in 1922 he became the bulwark of the organisation in Western Ontario. He established orthopaedic clinics in Sarnia and Seaforth as well as in London, and made contacts with the Service clubs in the area that were of great service in obtaining orthopaedic help for the people of Western Ontario-particularly for indigents and patients in outlying areas. The recent addition to the War Memorial Children's Hospital in London is largely the result of his efforts.

In Windsor, Dr Brockenshire has played the leading role in orthopaedic surgery. After completing his training in Edinburgh in 1932 he returned to Windsor and confined himself to the practice of orthopaedics. His influence has been felt very widely in the western part of Western Ontario.

VOL. 32 B, No. 4 , NOVEMBER 1950 


\section{ORTHOPAEDIC SURGERY IN MONTREAL}

About twenty years ago there were some eight to ten surgeons in Montreal who confine their practice to orthopaedic surgery alone. It was felt that we orthopaedic surgeons ougl to get together and know each other better: a meeting was called in the surgical amphitheatı of the Montreal General Hospital and was attended by Doctors Nutter, Turner, Forbe: Patterson, Derome, Caisse, Williamson, Breitman and Goldman. A quadriceps lengthenin operation was done by Dr Nutter assisted, if memory serves, by Goldman. That was th. beginning of the Montreal Orthopaedic Association, which is still going strong after so man years. We met once a month at various hospitals during the winter and spring. We rea papers, showed cases and discussed them. We kept no minutes then-we just grew. TI association attracted orthopaedic surgeons and others interested in orthopaedic surgery fror other cities-particularly from Ottawa and Quebec. It was always bilingual.

Dr J. Edouard Samson was one who was impressed by the success of the association an he went a step further-he suggested the foundation of a Canadian Orthopaedic Association

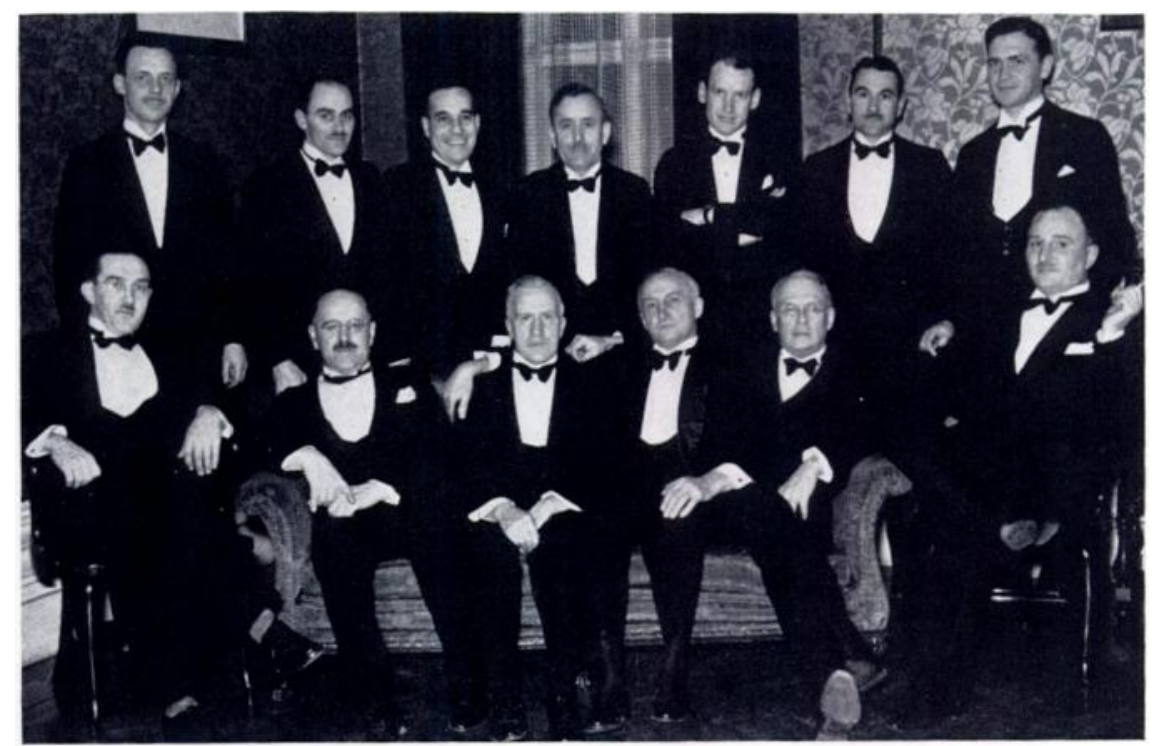

A group taken in 1939. Standing, left to right: Drs $\mathrm{C}$. Frenette, A Couturier, S. E. Goldman, Mr J. A. Duckett, I)r J. G. Shannon, a visitor, Dr Gordon Petrie. Sitting, left to right: Drs (i. Caisse, W. G. Turner, Rupert Derome, W. J. Patterson, J. A. Nutter and ․ T. Williamson.

After much discussion, and with some misgivings which have proved unfounded, his suggestic was accepted and the national association was founded in 194:) with J. A. Nutter as its fir: president. It prospered from the beginning; meetings have been held annually under tl successive presidencies of J. A. Nutter, Edouard Samson, R. I. Harris and Alexander Gibsol Dr J. A. Leo Walker has been the very active secretary of the association and his servic are invaluable.

In 1943 the Royal College of Physicians and Surgeons of Canada undertook tl certification of specialists and the writer was asked to represent the speciality of orthopaed surgery. No one was to be barred from practising orthopaedics, but only the holder of certificate from the Royal College could be regarded as a specialist. The first register include some forty-four names.

The doyen of orthopaedic surgeons in Montreal is undoubtedly IV. G. Turner, a memb of an old Quebec family, who graduated in arts at McGill Lniversity in 1896 and in Medicir 


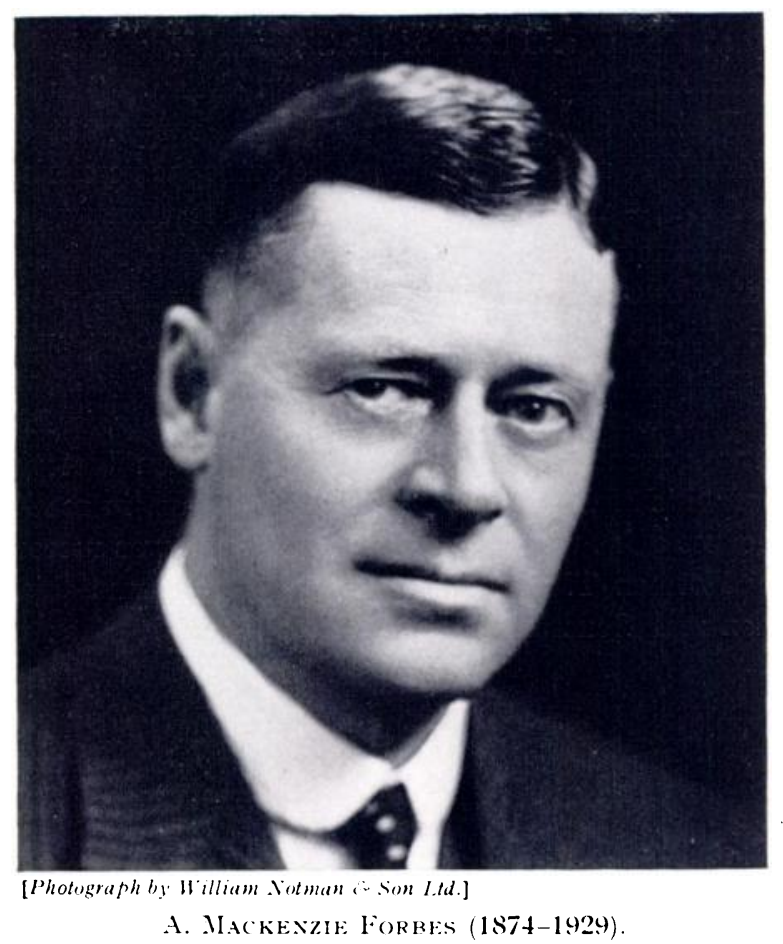

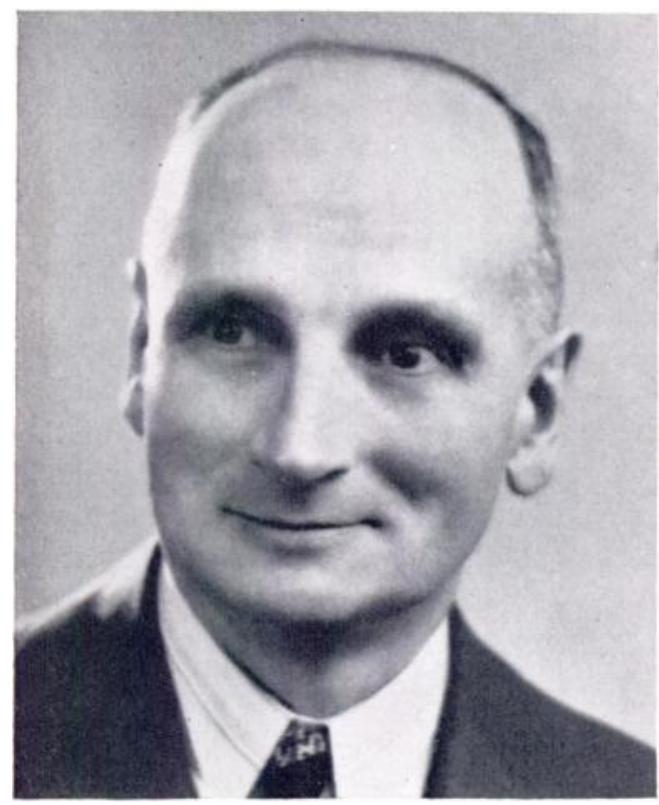

J. EDOLARD SAMSON.

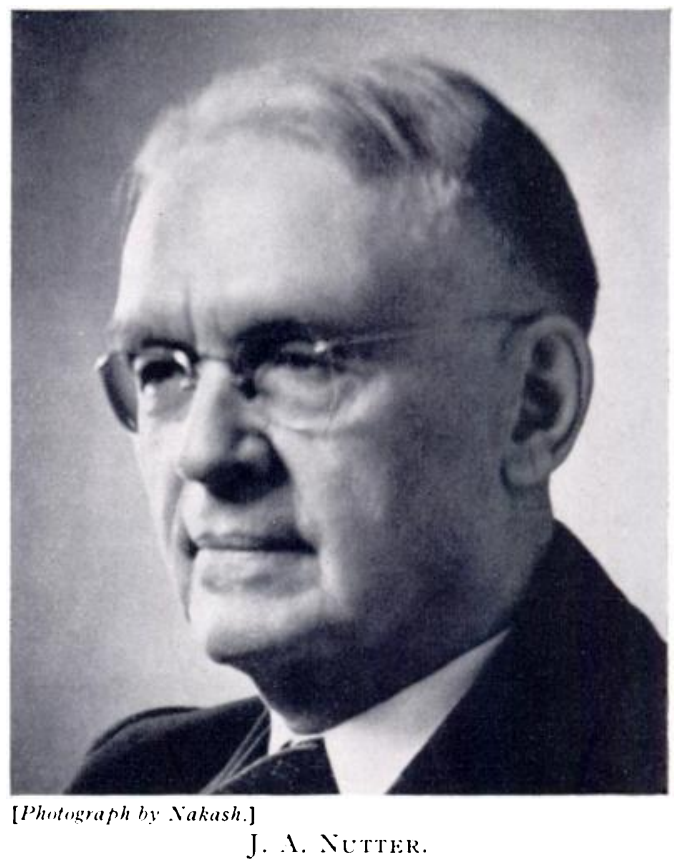

J. A. Nitrer.

VOL. $32 \mathrm{~B}$, NO. 4 , NOVEMBER 1950 
in 1900. He interned at the Montreal General Hospital, and later became medica superintendent. From this post he took a position at the Royal Victoria Hospital as surgeor in charge of orthopaedics in the department of general surgery. He was also clinical professor of orthopaedic surgery at McGill, and head of the Shriners' Hospital. He retired a few year: ago in favour of Dr Gordon Petrie. Another of the "old-timers" in Montreal was the lat Archibald MacKenzie Forbes, who practised orthopaedic surgery at the Montreal Genera Hospital and the Children's Memorial Hospital. The orthopaedic clinics were small in thost days-speaking now of 1911 -and there were seldom more than five or six patients thrict weekly. Forbes was a dramatic teacher. One of his favourite subjects was the differentia diagnosis between acute rheumatic fever and acute osteomyelitis near the knee. In lates years he was president of the American Orthopaedic Association; among his contribution: was an operation for spinal fusion. With his forceful personality he was able to enlist the financial support of the late Lord Atholstan, of the Montreal Star, in founding the Children': Memorial Hospital; it was opened in 1909 in memory of Queen Victoria. Forbes had a ful and bounding pulse, of which he was very proud: but it was, in reality, evidence of hear disease which was the cause of his untimely death in 1929. He was succeeded at the Children'؛ Memorial Hospital by Norman T. Williamson, who later became chief of the orthopaedic department at the Montreal General Hospital. He died in 1947 at the age of fifty-four

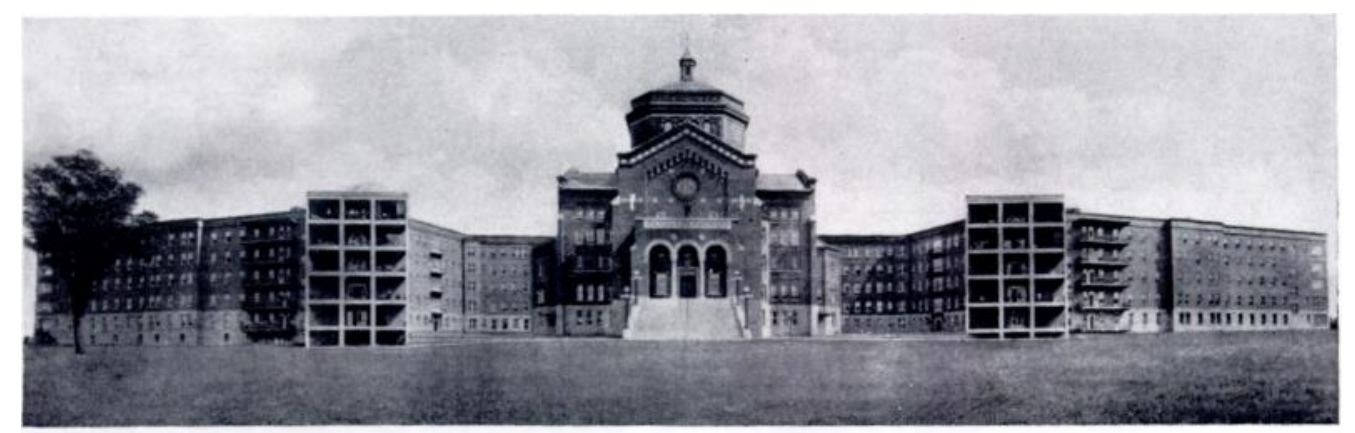

Montreal Sacred Heart Hospital.

Dr J. Edouard Samson came to Montreal in 1930, bringing Dr Ulric Frenette, his partne: and right-hand man, with him. Samson had graduated from Laval University in Queber and had studied with Hibbs and Albee in New York, and with Nové-Josserand in Lyons He now directs a unit of 200 beds at the Sacré Coeur Hospital at Certierville. He is said tı have the largest series of cases of arthroplasty of the knee in existence.

Among the prominent younger men in Montreal are Dr James G. Shannon, now chief o the orthopaedic department at the Montreal General Hospital; Dr S. E. Goldman of thi Montreal General, Women's General and Jewish General Hospitals; Dr J. C. A. Marchand who has recently been appointed Lecturer in Orthopaedic Surgery at the University of Ottawa and Dr Calixte Favreau, Professor of Orthopaedic Surgery at the University of Montrea since 1944.

\section{ORTHOPAEDIC SURGERY IN WESTERN CANADA}

In this part of Canada the pioneer of specialism in orthopaedic surgery was H. P. H Galloway. He was born in $\mathbf{1 8 8 6}$ and after assisting McKenzie in Toronto came to Winnipe in 1905 . Two years later he obtained official recognition in the speciality by being appointer lecturer in orthopaedic surgery in the medical school, while in the same year he was appointer to the staff of Winnipeg General Hospital as orthopaedic surgeon. Galloway continued it practice until his death in 1939 at the age of seventy-three. In 1919 he was President of th American Orthopaedic Association. He was a tireless worker and a resourceful and skilfu 
operator. Many contributions from his pen illustrated his thoughtful outlook; the most notable of these was his bold affirmation in 1920 that congenital dislocation of the hip joint in children promised better results if submitted to open operation than if treated by closed reduction.

Since these early days an increasing number of men have devoted themselves to orthopaedic work. In the city of Winnipeg alone there are fifteen such specialists, and in every large centre of population throughout Western Canada the story is similar. Regina, Saskatoon, Calgary, Edmonton, Vancouver and Victoria, all are served admirably by young and vigorous, well-trained men, contributing to the progress of the art and banded in associations of urban, provincial and national scope. Both in Winnipeg and Vancouver very close relationship is maintained with the adjoining sections of the United States.

In Winnipeg, as in other cities, hospital facilities are hardly adequate for the needs. Besides beds in the Winnipeg General, St. Boniface and the Children's Hospitals, there is a new Shriners' Hospital of forty beds opened in 1949. At the Veterans' Hospital, Deer Lodge, there is a staff of five visiting orthopaedic surgeons each of whom is engaged in clinical or

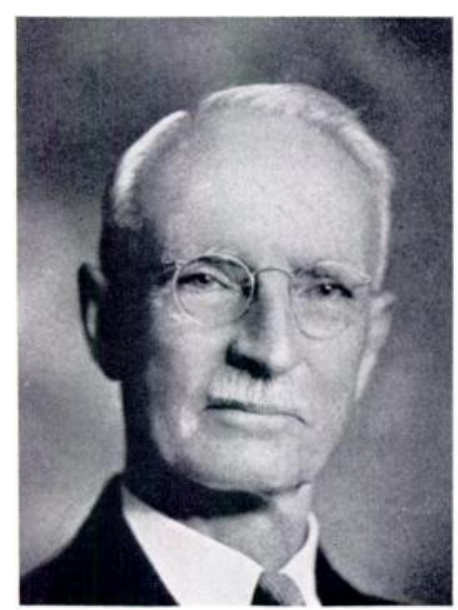

H. P. H. GALlowaY.

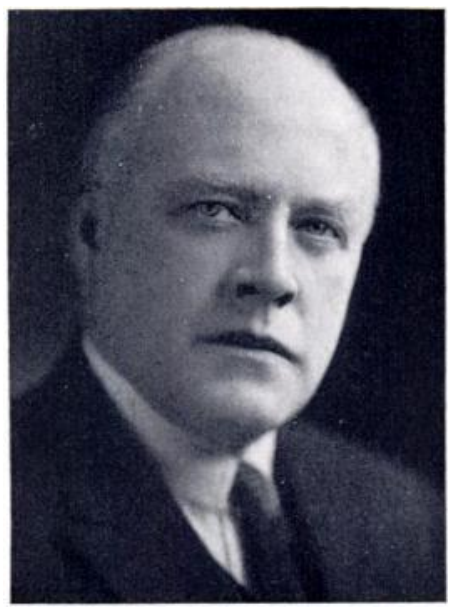

Peter A. McLenNaN.

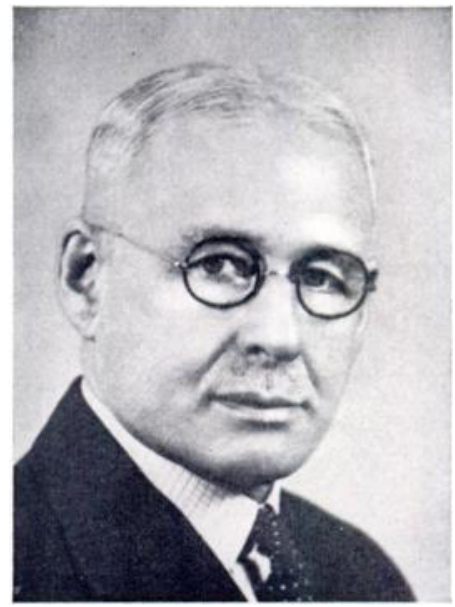

Frank P. Patterson.

experimental research as well as the practice of orthopaedics. The use of the fish-tail or clothespin graft for spinal fusion described in 1931, and the routine adoption of the "posterior" approach to the hip joint have been strongly advocated from Winnipeg. Tuberculosis of the bones and joints is still a matter of some consequence among the Indians who are cared for in sanitoria at Brandon and St. Boniface. In 1939 a fracture service was established in Winnipeg General Hospital on the lines of the Manchester fracture clinic. During the ten years since its inception some fifteen hundred cases have received treatment.

The majority of the men practising orthopaedics in Western Canada are still on the sunny side of forty-five. Most of them are Fellows of the Royal College of Surgeons of England or of Canada; in Winnipeg alone, three have obtained the Liverpool degree of Master of Orthopaedic Surgery. Throughout the whole of Western Canada the craft of orthopaedic surgery is in able, youthful and energetic hands.

\section{BRITISH COLUMBIA}

The history of orthopaedic surgery in British Columbia is short-so, indeed, is the history of medicine in this Province. At the beginning of the century there were two hundred doctors engaged in general practice and one specialist in diseases of the eye, ear, nose and throat. It was from this group of general practitioners that came the pioneers of traumatic and

VOL. $32 \mathrm{~B}$, No. 4, NOVEMBER 1950 
orthopaedic surgery. Two names stand out among them-Dr Peter A. McLennan and Dr Frank P. Patterson.

McLennan graduated from McGill University in 1898, began practice at Nelson in 1899 and moved to Vancouver in 1905 . He gained a wide reputation in surgery throughout the province. His name is closely linked with the development of the Vancouver General Hospital, whose staff he joined in 1912. When the hospital was reorganised in 1930 he became the first chief surgeon and continued in this post until his retirement. He was responsible for developing a fracture service which, though at first a part of the general surgical service, later came under the direction of the orthopaedic service. Fondly known as "Big Pete," Dr McLennan is still engaged in practice in Vancouver. He is a raconteur of great skill, and the historian and " elder statesman" of medicine in British Columbia.

Frank Patterson, a graduate of McGill in 1898, was the first in British Columbia to confine his work to orthopaedic surgery. He began practice in New Brunswick but moved to British Columbia in 1902, where he practised in Trail until 1908. Subsequently he studied in Britain, took the Fellowship of the Royal College of Surgeons of Edinburgh in 1909 and returned to general practice in Vancouver. After serving in the Canadian Army during the first world war he spent a year with Dr C. L. Starr at the Christie Street Hospital in Toronto, and returned to Vancouver in 1919 to confine his work to orthopaedic surgery. He became the first chief of the orthopaedic service in the Vancouver General and St Paul's Hospitals. He retired from the former in 1936, to be succeeded by the present chief, $\mathrm{Dr}$ J. R. Naden. Patterson died in 1938 at the age of sixty-two and was succeeded at St Paul's Hospital by D. Murray Meekison.

Those who followed McLennan and Patterson are all of a different generation and all except Meekison, who died in 1945, are still engaged in practice. At the present time there are fourteen orthopaedic surgeons in the Province; and the senior, Dr J. R. Naden, is still under fifty years of age. This is indicative of the short history of orthopaedics in British Columbia.

\section{THE MARITIME PROVINGES AND NEWFOUNDLAND}

The development of orthopaedic surgery as a speciality in the Maritime Provinces followed the first world war. Three medical officers from Nova Scotia availed themselves of the opportunity arranged by Sir Robert Jones to pursue postgraduate training at orthopaedic centres in England before returning to Canada for demobilisation. Two of these, O. G. Donovan and J. N. Lyons, returned to Halifax. Donovan held an appointment at Camp Hill, a hospital of the Department of Veterans' Affairs, and later became chief medical officer of the Nova Scotia Workmen's Compensation Board. Ross Miller returned to Amherst, Nova Scotia, where he carried on general practice with a leaning towards orthopaedics, and later became Director of Medical Services for the Department of Veterans' Affairs-an appointment which he held during World War II.

When the Canadian Medical Association held a meeting in Halifax in 1921, MacAusland of Boston presented a paper on his arthroplasty of the elbow joint. A young graduate from Dalhousie University, assisting the local committee on exhibits, met Dr MacAusland who became interested in him and not only suggested that he should pursue the speciality of orthopaedic surgery but offered an appointment on one of his hospital services in Boston. He pointed out that in his own practice many patients came from the Maritime Provinces and that there should be an excellent opening there for one who specialised in orthopaedics. He felt that someone should come back to Halifax, a university centre, properly trained in this speciality. The young graduate in medicine (who is the writer of this account) went to Boston to the MacAusland Clinic in September 1921. The work was interesting and fascinating; after working in the Crippled Children's clinics all over New England and spending six months in New York with Whitman and Hibbs he returned to Halifax in July 1923, opened an office and confined his practice to the speciality of orthopaedic surgery. 
In July 1924, Dalhousie University Health Centre opened an orthopaedic clinic staffed by J. N. Lyons and Tom B. Acker. This was the first teaching appointment in orthopaedics at Dalhousie University. In the same year Tom Acker was appointed to the staff of the Halifax Children's Hospital as an associate in the Department of Surgery and was allotted twelve orthopaedic beds. Dr Lyons died after being associated with the clinic for six years and was succeeded by John Acker. Acker, after graduation at McGill University and internship at the Montreal General Hospital under Nutter, went to the MacAusland Clinic in Boston for training. He returned to Halifax in 1925. The two brothers, Tom and John Acker, foresaw from their experience in Boston the opportunity of establishing crippled children's clinics in the Maritimes on the same pattern as those in the New England States.

The programme of the Canadian Red Cross Society in their Junior Red Cross Division included work for crippled children, and the Rotary Clubs had the treatment of crippled children as one of their community services. These two groups were brought together, and clinics for crippled children were started. By 1926 eighteen clinics were operating. They were visited at four- or six-monthly intervals and approximately 350 children were examined each year. Some were treated in local hospitals but most were sent to Halifax for special orthopaedic procedures. These crippled children's clinics are still going on.

In November 1949, shortly after the opening of the new Victoria General Hospital in Halifax, an orthopaedic service was established with an out-patient department staffed by John Acker, B. F. Miller and Tom Acker. Miller had recently returned from a course in orthopaedic surgery in England, obtaining the degree of M.Ch.Orth. in Liverpool and the diploma of F.R.C.S. in Edinburgh. The opening of this department in the new hospital further increased the facilities for teaching orthopaedics at Dalhousie University. At the present time there are plans for both the Children's Hospital and the Victoria General Hospital which will add approximately seventy-five orthopaedic beds for the treatment of adults and children.

The director of the Junior Red Cross in Prince Edward Island, Miss Mona Wilson, hearing of the work for crippled children in Nova Scotia, sought assistance in establishing similar clinics there. In 1926, under the sponsorship of the Junior Red Cross, the first clinic was opened, again with the assistance of the Rotary Club. An excellent organisation has developed, and approximately two hundred patients are examined at each clinic. Children who could not be treated in the local hospitals are sent to the Children's Hospital in Halifax for special orthopaedic procedures. As yet there is no orthopaedic specialist resident on Prince Edward Island.

The Department of Health of the Colony of Newfoundland, at the request of the late Dr L. E. Keegan, superintendent of the General Hospital in St John's, arranged to have orthopaedic problems surveyed and treatment carried out by a specialist. In November 1923, Tom Acker went to St John's and organised orthopaedic clinics. From then on regular trips were made, twice and sometimes three times each year. These clinics continued to be sponsored by the Commission of Government when they took over in Newfoundland; they were extended to other centres outside of St John's, including the Grenfell Hospital at Twillingate and the Paper Company Hospitals at Grand Falls and Corner Brook.

In 1937, Louis Conroy, a graduate of McGill University and one of the junior surgeons in St John's, showed interest in this work. He secured a Rockefeller Fellowship for training in orthopaedics at the Steindler and Campbell Clinics and on his return became established in this speciality and carried on the Crippled Children's Clinics. He now has two associates and an orthopaedic ward in the General Hospital.

In the Province of New Brunswick, orthopaedics as a speciality was first introduced by G. G. Corbett who formerly had done general practice in Saint John. About 1930, Dr Corbett went to Boston for a course at the MacAusland Clinic. Returning to Saint John, he opened an office specialising in orthopaedic surgery. He carried on this speciality for a few years

vol. 32 B, No. 4, NoveMber 1950 
until he was appointed medical officer of the New Brunswick Workmen's Compensation Board. In 1938, E. W. Ewart, after completing a course in orthopaedics at the Steindler and Campbell Clinics, opened an office in Moncton. He has been conducting clinics for crippled children under the Junior Red Cross, covering a large section of the Province. $\mathrm{He}$ has an orthopaedic service at the Moncton City Hospital and Hotel Dieu and is orthopaedic surgeon on the staff of the New Brunswick Tuberculosis Hospital. Recently O. J. White, who received his training at Gibson's Clinic in Winnipeg, joined Ewart in the practice of orthopaedics.

To give a proper background to an account of orthopaedic surgery in Alberta one must convey to the reader how new are most of the present-day institutions in the province. Alberta and Saskatchewan were carved out of the old North-West Territories in 1905. The famous westward march of the North-West Mounted Police took place in 1873. It was not until 1886 that the first transcontinental train ran over the main line of the Canadian Pacific Railway from Montreal to Vancouver. The University of Alberta was established in 1908 and in 1914 pre-medical teaching was started in the Faculty of Medicine. The first students to complete the full medical course in Alberta graduated in 1925 .

Before the first world war orthopaedic surgery was included in the work of the general practitioners. Of these the man who had most to do with the development of orthopaedic surgery was F. H. Mewburn. He graduated from McGill in 1881 and spent a year at the Montreal General Hospital. After practising in Winnipeg and Lethbridge he moved to Calgary in 1913 and limited his practice to surgery. During part of the first world war he served as head of the surgical division of No. 15 Canadian Hospital at Taplow, England, with the rank of Lieutenant-Colonel. Returning to Calgary after the war he was appointed Professor of Surgery and it was under his guidance that the department of surgery was organised. $\mathrm{He}$ saw to it that the subdivisions of surgery received proper recognition, and the department of orthopaedic surgery became a self-contained unit under its own director.

The first man to limit his practice entirely to orthopaedic surgery was Reggie Deane. He graduated from McGill in $\mathbf{1 8 9 8}$ and was later associated with Colonel Mewburn in Lethbridge. In 1911 he moved to Calgary to practise general surgery. After the first world war he studied orthopaedic surgery in England and on his return he specialised in this branch exclusively until his death in 1941.

F. H. H. Mewburn, a son of Colonel Mewburn, was the second individual to confine his practice to orthopaedics. He graduated from McGill in 1914 and after military service in the first world war returned to Edmonton in 1919. Later he studied orthopaedics in Boston and on his return in 1923 he was appointed lecturer in orthopaedics in the University of Alberta. In 1931 he became Clinical Professor of Orthopaedic Surgery. Although he retired from teaching in 1948 he is still in practice.

Graham Huckell was the third orthopaedic surgeon in the province. During the epidemic of poliomyelitis in 1927 he became associated with F. H. H. Mewburn in Edmonton and in 1930 he opened his office for the practice of orthopaedic surgery. He succeeded Dr Mewburn as Clinical Professor of Orthopaedic Surgery.

In recent years a number of younger men, trained in England, the United States and Canada, have returned to Alberta to practise orthopaedics, and the speciality is now well established as a separate branch of surgery. The Alberta Orthopaedic Association was formed in 1948 and meets twice a year, in Calgary and in Edmonton. If till now there have been no new discoveries and little research it is because all our energies have been expended in organisation. The stage is now set for new progress and much will be accomplished in the future. 